\title{
Acting on Sustainability
}

\author{
Vaughan Prain
}

Published online: 29 October 2011

(C) Springer Science+Business Media B.V. 2011

\section{Changing science}

This special issue of RISE makes a timely contribution to the growing literature on research on teaching and learning about socio-scientific issues (SSI), particularly focusing on the topic of sustainability. The SSI agenda when applied to school science represents a significant attempt to reconceptualize this subject's fundamental rationale, goals, and methods. The traditional curriculum where students confirm canonical theories, concepts and processes through predictable classroom-based inquiry, is replaced by study of complex science-based real-world problems, where science is understood as a powerful resource, knowledge base, and repertoire of methods and strategies, for contributing to possible solutions. The traditional certainties around what science content should be studied, how and why, and what should count as optimal student learning are all problematized by this shift to an emphatically applied focus. While researchers in this field now broadly agree on the rationale for a SSI orientation, and concur about broad principles for its enactment, many areas remain under-researched and emergent. The seven papers in this special issue collectively contribute to this agenda, but also indicate the diversity of theoretical and practical matters at stake. In this short response I highlight new insights provided by these articles, as well as future challenges arising from this work.

\section{SSI approaches so far}

There is now a substantial literature characterizing SSI approaches to science education as a necessary reform to science curricula that focuses on controversial, socially relevant issues within this curricula (Cross \& Price, 1996; Davies, 2004; Hodson, 2003; Kolstø, 2001; Lee \& Witz, 2009; Levinson, 2006; Ratcliffe \& Grace, 2003; Sadler et al. 2007; Zeidler, 2003). The SSI movement insists that ethical aspects of social issues need to be linked with conceptual and methodological approaches in science to address real-world problems. As

V. Prain $(\bowtie)$

La Trobe University, Bendigo, VIC, Australia

e-mail: V.Prain@latrobe.edu.au 
noted by Klosterman, Sadler and Brown (this issue), SSIs tend to be "ill-structured in that they are complex, subject to various knowledge domains, and areas of open inquiry", where solutions are multiple and uncertain, and are necessarily influenced by science concepts and theories but also by "political, economic, humanistic and ethical factors". Therefore decision-making on SSIs, whether in theory or practice, needs to consider scientific inputs but also other forms of knowledge and values.

This consensus about the broad key features of SSI approaches raises many challenges and questions, some of which are taken up by researchers in this issue of RISE. These include questions about the place and authority of scientific concepts and methods in addressing SSIs. What exact role or roles should these concepts and methods play in learner understanding or reasoning around a SS1? What is entailed in this reasoning, and are there patterns of reasoning broadly applicable to all or most SSIs? Given that SSIs include topics as diverse as gene therapy, mobile phone use, and resource management of marine ecosystems, are more pluralistic approaches needed to identify current and desirable student reasoning processes? There is also the challenge of recruiting science teachers to this curricular agenda, with its uncertainty of science content and learning outcomes, and its assertion that students need to make ethical judgments across multiple domains. Another set of questions focus on what should count as effective teaching and successful student learning within a SSI framework, including student character development of ethical responsibility as citizens. Understanding and estimating probability and risk in scientific terms around a SSI is one matter, but incorporating this knowledge into an ethical action plan represents a new challenging set of learning objectives. As well, there are also diverse views on what research methods should be used to assess learning outcomes from engagement with SSIs.

\section{Theorizing the roles of science in engaging with SSIs}

A core issue in engaging with SSIs is conceptualizing the role or roles science should or could play in this form of inquiry and problem-solving. The contributors here broadly agree that science knowledge and research (both primary and secondary) are critical resources for this inquiry, but need to be contextualized and informed by relevant ethical, cultural, and pragmatic considerations. Robottom (this issue) suggests a broad general principle that scientific knowledge and approaches are necessary but insufficient to address SSIs, because these issues always link philosophical and empirical questions around contested values. He argues that SSIs need to be approached from socio-critical perspectives that address stakeholder concerns for long-term community viability, where outcomes should be understood as options for actions in a "specific time/space context". In this kind of open or hybrid inquiry, the science knowledge and methods used or developed to engage with SSIs are contingent, unpredictable and opportunistic, and should be judged pragmatically by their capacity to shape acceptable outcomes for participants. Lange (this issue) concurs, noting the value of scientific modelling, not just in prediction and support of student understanding, but in conceptualizing, representing, clarifying, deducing, reasoning and problem-solving: "all are critical functions for exploring consequences, conditions and opportunities for sustainable development". For Bencze, Sperling and Carter (this issue), student-led open-ended correlational studies can provide a valuable tool for engaging with SSIs.

Simonneaux and Simonneaux (this issue) suggest that the roles science knowledge and methods can play in a SSI will vary, depending on participant understandings, purposes, and practices. They make a persuasive case for multiple roles for science-based knowledge 
and methods in various kinds of valuable school-based SSI inquiry. In one example, students use "resolved" knowledge and methods, such as modeling of empirical data, to learn about the complexities of eco-socio system management in one location, whereas in another project students plan, enact and evaluate strategies to support water use for sustainability of their local community. In another study, students use evidence based on "more or less consolidated scientific knowledge" to judge environmental impacts in production/processing/distribution chains through identifying energy consumption, where results are debatable depending on the chosen indicators of this consumption. The authors make a convincing case for recognizing that the diverse nature of SSIs and the broad range of intended learning outcomes necessitate diverse approaches to methods for generating, applying and critiquing scientific and other forms of knowledge. They note that pragmatic approaches to problem-solving may strongly engage learners in meaningful tasks, but also "cool down" the analyses of controversies and scientific uncertainties. By offering a typology of "educational configurations" (that they promptly recognize as incomplete), they provide a valuable lead to conceptualizing diverse functions that science knowledge and methods can serve in student engagement with SSIs.

\section{Effective pedagogy for SSI inquiry}

All the researchers in this special issue broadly agree that student "participation" in inquiry is critical for successful learning outcomes, noting that the most advanced form of participation entails informed student action based on primary and/or secondary research. For Bencze, Sperling and Carter (this issue), students need to demonstrate their capacity to be "citizen activists", evident when they (a) show concern for an SSI, (b) indicate an intention to act on this matter, (c) believe in their capacity to act, and (d) plan and implement actions relevant to their concerns. Students need to learn how to prepare to be "social actors" (Lange, this issue), to be critical thinkers who have attained both "scientific and political literacy" (Simonneaux \& Simonneaux, this issue). For Klosterman, Sadler and Brown (this issue), students should develop understandings and make decisions that "promote more deliberate care of our planet".

Across analyses of various case studies in this special issue, the researchers also agree about the broad pedagogical principles that are likely to engender this student activism. These include: (a) motivation of the students' will to act, (b) sustained opportunities for student agency in engaging with the SS1, especially in a context of integrated studies rather than singular subjects, (c) opportunities for debate with actual or simulated stakeholders, and (d) ample opportunities to re-represent their understandings/commitments/actions around SSIs. On the motivation question, Lange (this issue) makes the shrewd point that students need to own a sense of collective vulnerability on the SSI that is not allayed by externally-imposed technocratic solutions, nor is so overwhelming as to inhibit action. He suggests that prospective scenarios, targeted to the developmental capacities of different student age groups, can motivate students to use science modeling to "delineate and understand the issues at stake", thus leading to collective action after extensive debate around relevant scientific and other perspectives. He notes that the complexity of SSIs demands the use of cross-disciplinary approaches, with "necessary cooperation between the sciences and humanities". For Bencze, Sperling and Carter (this issue), student ownership of inquiry into a SSI is a critical pedagogical principle, where students view themselves as "knowledge constructors" who are given scope by their teacher to design, implement, and disseminate their findings. As noted by the researchers, this implies that science teachers 
are strongly committed to student activism, have the necessary skill and will to motivate, guide and support effective student inquiry of this kind, and are confortable with crosscurricular projects.

In their analyses of science teacher opportunistic use of non-instructional mass media to address SSIs, Klosterman, Sadler and Brown (this issue) noted various missed pedagogical opportunities. While the teachers in the reported case studies used mainly print-based reports as motivational resources, the teachers tended to constrain student roles by not expecting students to access additional material, undertake evaluation of sources for accuracy, adequacy, bias, credibility and usability, or make informed personal decisions on the SSI. The researchers suggest that student construction of media on SSIs is another under-utilized pedagogical opportunity for engagement, and "could lead to new forms of participatory science literacy". This echoes the strong advocacy by Bencze, Sperling and Carter (this issue) and Tomas and Ritchie (this issue) of the theoretical and practical value of students constructing re-representations of their SSI understandings and findings. These representations can function as both science-based knowledge claims and evidence of ethical understanding of the SSI. In summary, researchers in this issue contribute further to a growing set of prescriptions about effective conditions for student engagement with SSIs. However, as noted by various contributors, there is a need to highlight successful practices, provide more teacher professional development, and to encourage more cross-curricular and school-based prioritization of the value of SSIs as central to a contemporary curriculum.

\section{Researching student learning through engaging with SSIs}

This is probably where the researchers in this special issue of RISE make more innovative contributions to the literature, partly because successful engagement with SSIs implies changes to students' dispositional, procedural and propositional knowledge, as well as their intentions to decide and act. This complexity of intended outcomes has led the researchers to use diverse quantitative and qualitative assessment frameworks and probes, including teacher and student interviews and analyses of student artefacts (Bencze, Sperling \& Carter, this issue, Klostereman, Salder \& Brown, this issue, Lange, this issue, Simonneaux \& Simonneaux, this issue), speech complexity analysis (Lange, this issue), as well as discourse analysis of videotaped lessons (Bravo-Torija \& Jiminez-Aleixandre, this issue), and emotion surveys (Tomas \& Ritchie, this issue). Lange (this issue) also conducted interviews with students to identify their "propensity to act" on SSIs.

Bravo-Torija and Jiminez-Aleixandre (this issue) sought to identify students' discursive moves as they engaged in a learning sequence where they were expected to integrate two models (ecological efficiency, and population maintenance) as the basis for developing a sustainable management plan for resources in a marine ecosystem. The sequence implied increasing complexity and more demanding reasoning towards the task's completion. The researchers' use of discourse analysis highlights both students' meaning-making practices "on the fly" and the critical role that timely scaffolding can play in drawing out links between students relevant contextual knowledge and various applications/instances of "energy flow" in this topic. In this regard, discourse analysis also provides valuable insights into the students' informal reasoning, a key area of research in student engagement with SSIs. Tomas and Ritchie (this issue) undertake the unusual task of seeking to identify and track students' expressions of positive emotions in engaging with narrative writing on a SS1. There is now compelling evidence of the central role of affect in guiding an individual's reasoning and judgment, as noted by Damasio (1994) and others, and therefore 
an explicit focus on student scholarly pleasure, pride in achievement and heightened attentiveness are relevant to assessing dispositional goals associated with successful "ownership" of an SSI. For Lange (this issue), the level of student ownership of an SSI can be tracked through grammatical analyses of students' pronoun choices (is this about me or someone else?), verb choice ("we can reduce our consumption"), and student willingness to act or defer problems to future generations. Collectively, the research methods outlined in this issue provide some valuable fresh leads in ways to monitor and evaluate student responses to SSIs.

\section{Challenges for the future}

This special issue indicates that there is a range of continuing challenges for science education researchers in this area. There is the need, as always in an emergent field that is drawing on diverse frameworks, to continue to consolidate shared conceptual and methodological perspectives. This special issue contributes directly to this process. Despite the different theoretical orientations and constructs evident in these papers, there is considerable convergence about the need to reform the science curriculum and what should count as success in student learning around SSIs, and how and why. However, there is also a need to continue systematic research into the processes that enable or constrain this agenda, where these processes are broadly understood in terms of: (a) national and local curricular expectations, (b) student task demands, (c) teacher and student roles across a range of types of inquiry; (d) individual student and group informal reasoning and decisionmaking, and (e) refinement of pedagogical principles to guide and inform effective teaching and learning around SSIs. This agenda will be advanced by compelling, explanatory accounts of successful teacher and student negotiation of this kind of inquiry.

A further challenge is for this research to continue to draw productively on frameworks and methods from other discipline areas to develop appropriate conceptual and methodological sophistication for interpreting complex processes and goals around SSIs. While Layton's (1986) values-based reasoning framework provided useful early leads for some researchers on analysis of ethical dimensions of SSIs, there is an ongoing need for additional perspectives that recognize the cross-disciplinary nature of this agenda. The application of discourse analysis (Bravo-Torija and Jiminez-Aleixandre, this issue), and critical media studies (Klostereman, Salder \& Brown, this issue) are instructive in demonstrating (a) the necessarily constructed and partial nature of the knowledge claims made about SSIs, and (b) the symbolic and cultural resources needed to generate and judge this knowledge.

\section{References}

Cross, R. T., \& Price, R. F. (1996). Science teachers' social conscience and the role of controversial issues in the teaching of science. Journal of Research in Science Teaching, 33, 319-333.

Damasio, A. (1994). Descartes' error: emotion, reason and the human brain. New York: Putnam Publishing.

Davies, I. (2004). Science and citizenship education. International Journal of Science Education, 26(14), $1751-1764$.

Hodson, D. (2003). Time for action: science education for an alternative future. International Journal of Science Education, 25, 645-670.

Kolstø, S. D. (2001). Scientific literacy for citizenship: tools for dealing with the science dimension of controversial socioscientific issues. Science Education, 85, 291-310. 
Layton, D. (1986). Revaluing science education. In P. Tomlinson \& M. Quinton (Eds.), Values across the curriculum. London: Falmer Press.

Lee, H., \& Witz, K. G. (2009). Science teachers' inspiration for teaching socio-scientific issues: disconnection with reform efforts. International Journal of Science Education, 31(7), 931-960.

Levinson, R. (2006). Towards a theoretical framework for teaching controversial socio-scientific issues. International Journal of Science Education, 28(10), 1201-1224.

Ratcliffe, M., \& Grace, M. (2003). Science education for citizenship. Maidenhead: Open University Press.

Sadler, T., Barab, S., \& Scott, B. (2007). What do student gain by engaging in socioscientific inquiry? Research In Science Education, 37(4), 371-391.

Zeidler, D. L. (Ed.). (2003). The role of moral reasoning on socioscientific issues and discourse in science education. Dordrecht: Kluwer Academic Publishers. 